\title{
Produtividade de grãos de milho e massa seca de braquiárias em consórcio no sistema de integração lavoura-pecuária
}

\author{
Corn grain yield and dry mass of Brachiaria intercrops in the crop-livestock integration system
}

\author{
Cristiano Magalhães Pariz ${ }^{{ }^{*}}$ Marcelo Andreotti ${ }^{I I}$ Mariana Vieira Azenha ${ }^{\mathrm{I}}$ \\ Antonio Fernando Bergamaschine ${ }^{\mathrm{III}}$ Luiz Malcolm Mano de Mello ${ }^{\mathrm{II}}$ Ronaldo Cintra Lima ${ }^{\mathrm{II}}$
}

RESUMO

\begin{abstract}
Objetivou-se avaliar as produtividades de grãos de milho e massa seca de braquiárias em duas modalidades de consórcio em sistema de integração lavoura-pecuária no período de inverno-primavera em região do Cerrado. O experimento foi conduzido no ano de 2006, na Fazenda de Ensino, Pesquisa e Extensão (FEPE), pertencente à Faculdade de Engenharia (FE/UNESP - Campus de Ilha Solteira), localizada no município de Selvíria, MS. O delineamento experimental utilizado foi de blocos casualizados, em esquema fatorial 4x2, com cinco repetições. Os tratamentos constituíramse de quatro espécies de braquiárias (Brachiaria brizantha cv. 'Marandu', Brachiaria decumbens, Brachiaria ruziziensis e Brachiaria híbrido $\mathrm{cv}$. 'Mulato II') consorciadas na linha e a lanço no momento da semeadura do milho. Avaliaram-se os componentes da produção, a produtividade do milho, bem como a massa seca das braquiárias após a colheita do milho. As forrageiras consorciadas a lanço, com destaque para a Brachiaria ruziziensis proporcionaram menor desenvolvimento das plantas de milho e menores valores dos componentes da produção, bem como da produtividade de grãos. Apesar de satisfatórias produtividades de massa seca (acima de $2.500 \mathrm{~kg}$ $h a^{-1}$ ), com exceção da Brachiaria brizantha, as demais espécies consorciadas a lanço foram superiores, com destaque para a Brachiaria decumbens e a Brachiaria ruziziensis que apresentaram maior adaptabilidade e produtividade de forragem no consórcio com milho em sistema de integração lavoura-pecuária.
\end{abstract}

Palavras-chave: Brachiaria brizantha $c v$. 'Marandu', Brachiaria decumbens, Brachiaria ruziziensis, Brachiaria híbrido cv. 'Mulato II', sistema plantio direto, Zea mays L.

\begin{abstract}
The objective of this research was to evaluate the corn grain yield and dry mass of Brachiaria forage in two intercrop in crop-livestock integration system at winter-spring season in the Brazilian Cerrado. The experiment was carried out during the 2006 growing season, at the Engineering College Experimental Station (FE/UNESP, Ilha Solteira Campus), Selviria, Mato Grosso do Sul State, Brazil. The experimental design used was in randomized blocks, in factorial scheme (4x2), with five replications. The treatments were four Brachiaria species (Brachiaria brizantha $c v$. 'Marandu', Brachiaria decumbens, Brachiaria ruziziensis and Brachiaria híbrido $c v$. 'Mulato II') intercropped on rows and spread on total area during corn sowing. It were evaluated the production components, the grain corn yield and the dry mass yield of Brachiaria forage after the corn harvest. The forages intercropped at spread on total area, with emphasis to Brachiaria ruziziensis, provided lower development of corn plants, lower values of production components and grain yield. Although the dry mass yield was satisfactory (above 2,500kg $\left.h a^{-1}\right)$, except for Brachiaria brizantha, the other species intercropped at spread on total area were higher, with highlight to Brachiaria decumbens and Brachiaria ruziziensis that showed greater adaptability and forage yield at corn intercrop in croplivestock integration system.
\end{abstract}

Key words: Brachiaria brizantha $c v$. 'Marandu', Brachiaria decumbens, Brachiaria ruziziensis, Brachiaria hibrid cv. 'Mulato II', no-tillage system, Zea mays $L$.

'Programa de Pós-graduação em Zootecnia, Faculdade de Medicina Veterinária e Zootecnia (FMVZ), Universidade Estadual Paulista "Júlio de Mesquita Filho" (UNESP), CP 560, 18618-000, Botucatu, SP, Brasil. E-mail: cmpzoo@gmail.com. *Autor para correspondência.

IIDepartamento de Fitossanidade, Engenharia Rural e Solos, Faculdade de Engenharia Rural e Solos, UNESP, Ilha Solteira, SP, Brasil. "IIDepartamento de Biologia e Zootecnia, Faculdade de Engenharia, UNESP, Ilha Solteira, SP, Brasil. 


\section{INTRODUÇÃO}

Dentre as premissas básicas para a sustentabilidade agropecuária destacam-se a recuperação das áreas degradadas, a preservação ambiental, o aumento da competitividade no mercado agrícola, a redução dos custos de produção, a agregação de valores e o uso intensivo da área, principalmente sob lavoura, durante todo o ano, devendo ser mantidas as altas produtividades. Nesse contexto, uma das alternativas para se angariar todas essas premissas é a integração lavoura-pecuária (ILP) em sistema semeadura direta (SSD), envolvendo o cultivo de culturas graníferas e a produção pecuária, com o mínimo de interferência entre elas, visando a gerar resultados socioeconômicos e ambientais positivos (KLUTHCOUSKI \& YOKOYAMA, 2003; ALLEN et al., 2007).

A ILP tem se tornado opção vantajosa, beneficiando duas atividades de importância econômica, proporcionando ganhos mútuos ao produtor, além do que, a maioria das evidências sugere que esse sistema possui melhores aspectos ambientais do que modernos sistemas de monocultura dependentes da alta utilização de insumos, como fertilizantes, inseticidas e herbicidas (ALLEN et al., 2007; SULC \& TRACY, 2007).

Em áreas de lavoura com solos devidamente corrigidos, foi preconizado o sistema consorciado de culturas graníferas com forrageiras tropicais, principalmente as do gênero Brachiaria, o qual apresenta grandes vantagens, pois, na maioria dos casos, pouco altera o cronograma de atividades do produtor, é de baixo custo e não exige equipamentos especiais para sua implantação (KLUTHCOUSKI et al., 2000).

No entanto, o conhecimento do comportamento das espécies na competição por fatores de produção torna-se de grande importância para o êxito da produtividade satisfatória da cultura de grãos e da formação da pastagem, evitando que a competição existente entre as espécies inviabilize o cultivo consorciado (KLUTHCOUSKI \& YOKOYAMA, 2003).

Tal sistema tem sido objeto de estudo de vários pesquisadores na região do Cerrado, conforme revisões realizadas por KLUTHCOUSKI et al. (2000), ALVARENGA et al. (2006), MACEDO (2009), EUCLIDES et al. (2010), os quais relataram que, no geral, a presença da forrageira não afetou a produtividade de grãos de milho, bem como a deposição do fertilizante de semeadura, misturado com as sementes da espécie forrageira, em maiores profundidades, permite o atraso da emergência, de maneira a diminuir a competição com a cultura produtora de grãos.
Outras formas de ILP com pastagens anuais de inverno, em cultivo exclusivo ou em consórcio de gramíneas e leguminosas, têm sido estudadas na região Sul do Brasil (FONTANELI et al., 2006; SILVA et al., 2007; LUNARDI et al., 2008; CARVALHO et al., 2010), com resultados favoráveis principalmente em relação ao aumento da produtividade de grãos de milho e soja sobre os resíduos das pastagens após a dessecação, conforme revisão de BALBINOT JÚNIOR et al. (2009).

Contudo, a maioria dos trabalhos neste sistema de produção agrícola avalia a utilização da Brachiaria brizantha e Brachiaria decumbens, havendo carência de informações quanto à Brachiaria ruziziensis e à Brachiaria híbrido cv. 'Mulato II'. Além disso, o sistema de consórcio tem sido estabelecido para produção de forragem entre o período de outonoprimavera e, posteriormente, a dessecação desta para o aporte de palha ao SSD, ou mesmo, apenas para formação de palhada. Dessa forma, objetivou-se avaliar a produtividade de grãos de milho e massa seca de espécies de braquiárias em duas modalidades de consórcio na integração lavoura-pecuária no período de inverno-primavera em região de Cerrado.

\section{MATERIAL E MÉTODOS}

O experimento foi desenvolvido no ano de 2006, na Fazenda de Ensino, Pesquisa e Extensão, pertencente à Faculdade de Engenharia, Campus de Ilha Solteira - FE/UNESP, área de Produção Vegetal, localizada no município de Selvíria, MS (20²2’05'S e $51^{\circ} 22^{\prime} 02^{\prime \prime} \mathrm{W}$, altitude de $335 \mathrm{~m}$ ). O clima, conforme a classificação de Köppen, é o tropical úmido com estação chuvosa no verão e seca no inverno, do tipo fundamental Aw, e a precipitação média anual é de $1370 \mathrm{~mm}$. Os dados meteorológicos coletados no decorrer do estudo estão apresentados na figura 1.

O solo da área experimental foi classificado como Latossolo Vermelho distroférrico textura argilosa (EMBRAPA, 1999). Em julho de 2006, os atributos físicos e químicos na camada de 0 a $0,20 \mathrm{~m}$ do solo da área experimental foram: densidade do solo $=1,25 \mathrm{~kg} \mathrm{dm}^{-3}$; macro, micro e porosidade total $=0,163,0,314$ e $0,477 \mathrm{~m}^{3}$ $\mathrm{m}^{-3}$, respectivamente; $\mathrm{pH}\left(\mathrm{CaCl}_{2}\right)=5,2 ; \mathrm{MO}=26 \mathrm{~g} \mathrm{dm}^{-3}$; $\mathrm{H}+\mathrm{Al}=27 \mathrm{mmol}_{\mathrm{c}} \mathrm{dm}^{-3} ; \mathrm{P}($ resina $)=24 \mathrm{mg} \mathrm{dm}^{-3} ; \mathrm{K}^{+}, \mathrm{Ca}^{2+} \mathrm{e}$ $\mathrm{Mg}^{2+}=3,2 ; 24$ e $13 \mathrm{mmol}_{\mathrm{c}} \mathrm{dm}^{-3}$, respectivamente, e $\mathrm{V}=60 \%$. A área experimental apresentava um histórico de quatro anos de SSD (cultura anterior feijão).

O delineamento experimental utilizado foi o de blocos casualizados, em esquema fatorial $4 \times 2$, com cinco repetições. Os tratamentos constituíram-se de quatro espécies de braquiárias (Brachiaria brizantha cv. 'Marandu', Brachiaria decumbens, Brachiaria 


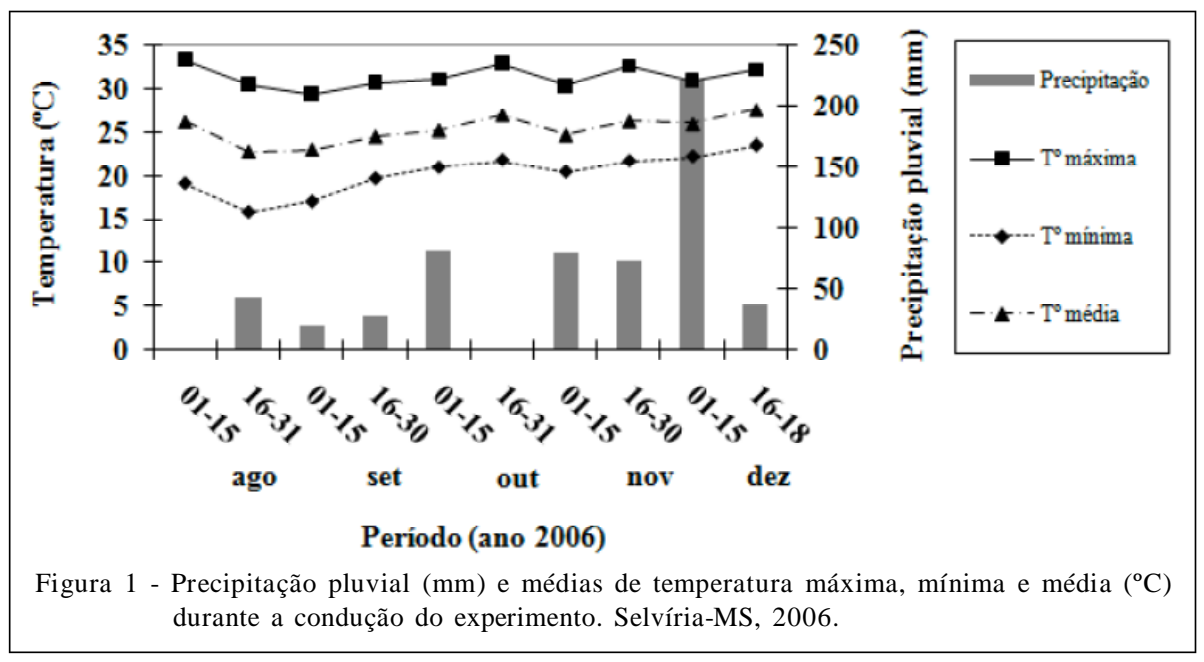

ruziziensis e Brachiaria híbrido cv. 'Mulato II') consorciadas na linha e a lanço, na semeadura da cultura do milho. Cada parcela foi constituída por 6 linhas de $10 \mathrm{~m}$ de comprimento, espaçadas em $0,90 \mathrm{~m}$, perfazendo uma área total de $54 \mathrm{~m}^{2}$. O híbrido de milho utilizado foi o AG 2040 (híbrido simples), de ciclo médio, com finalidade para produção de grãos.

Em 11/08/2006, realizou-se a dessecação da área experimental, com a utilização dos herbicidas glyphosate, na dose de $1,44 \mathrm{~kg}$ do ingrediente ativo (i.a.) ha ${ }^{-1}$ e 2,4-D amina, na dose de $670 \mathrm{~g}$ do i.a. ha ${ }^{-1}$, utilizando volume de aplicação de $250 \mathrm{~L} \mathrm{ha}^{-1}$. A semeadura do milho em consórcio com as forrageiras foi realizada em 15/08/2006, por meio de semeadora adubadora de discos para SSD, visando a atingir a densidade populacional de 60.000 plantas por hectare. As sementes de milho apresentavam índice mínimo de germinação de $95 \%$ e foram tratadas com o inseticida Thiodicarb, na dose de $700 \mathrm{~g}$ do i.a. para $100 \mathrm{~kg}$ de sementes. Independente da modalidade de consorciação (linha ou lanço), as sementes forrageiras foram semeadas na quantidade de 450 pontos de valor cultural (VC) ha ${ }^{-1}$, visando a estabelecer entre 8 e 10 plantas por $\mathrm{m}^{2}$. Nos tratamentos em que as forrageiras foram semeadas na linha do milho, as sementes foram misturadas ao adubo no momento da semeadura e acondicionadas no compartimento de fertilizante da semeadora adubadora sendo distribuídas na profundidade de $0,08 \mathrm{~m}$. Para a semeadura a lanço, as sementes de braquiária foram distribuídas manualmente a lanço e incorporadas ao solo com uma operação de gradagem na profundidade de $0,05 \mathrm{~m}$, antes da semeadura do milho. Das espécies utilizadas, apenas as sementes de B. ruziziensis eram peletizadas, visto que algumas empresas vêm preconizando a utilização destas em sistemas de ILP, sobretudo em consórcio com arroz, soja, milho e sorgo. A adubação mineral de semeadura constou de $24 \mathrm{~kg} \mathrm{ha}^{-1}$ de N, $84 \mathrm{~kg} \mathrm{ha}^{-1}$ de $\mathrm{P}_{2} \mathrm{O}_{5}$ e $48 \mathrm{~kg} \mathrm{ha}^{-1}$ de $\mathrm{K}_{2} \mathrm{O}$ (300 $\mathrm{kg} \mathrm{ha}^{-1}$ do fertilizante 0828-16). A área foi irrigada por aspersão (pivô central), quando necessário, em função de déficits hídricos, durante todo o período experimental.

A emergência do milho ocorreu sete dias após a semeadura (22/08/2006) e das forrageiras em 26/ 08/2006. Aos 20 dias após a emergência do milho (DAE), efetuou-se o controle de pragas, aplicando inseticida a base de delthametrin, na proporção de $5 \mathrm{~g} \mathrm{ha}^{-1}$ do i.a.; simultaneamente, empregou-se, em mistura de tanque, herbicida a base de atrazine, na dose de $2.500 \mathrm{~g} \mathrm{ha}^{-1} \mathrm{do}$ i.a. Quando a cultura do milho atingiu o estádio fenológico V6 (seis folhas totalmente expandidas), em 15/09/2006, procedeu-se à adubação de cobertura,

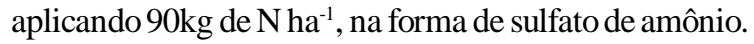

A colheita manual do milho foi realizada em 18/12/2006 (110 DAE) e avaliaram-se os componentes da produção (10 espigas escolhidas aleatoriamente dentro de cada parcela) e a produtividade de grãos a $130 \mathrm{~g} \mathrm{~kg}^{-1}$ de umidade ( $8 \mathrm{~m}$ das duas linhas centrais da parcela). Na mesma data, realizou-se a colheita das braquiárias, em uma área de $0,25 \mathrm{~m}^{2}$ (três amostragens por parcela), com auxílio de um quadrado de metal de $0,5 \times 0,5 \mathrm{~m}$, nas alturas de corte recomendadas por PIRES (2006) para cada espécie. Após a colheita, o material foi pesado e posteriormente colocado em estufa de circulação forçada de $\operatorname{ar}\left(65^{\circ} \mathrm{C}\right)$ até massa constante, para determinação da porcentagem de matéria seca (\%MS) e produtividade de massa seca (PMS) em kg ha ${ }^{-1}$.

Para testar a hipótese de normalidade, realizou-se o teste de SHAPIRO \& WILK (1965) a $1 \%$ de significância. Os dados de cada atributo do milho e das braquiárias foram submetidos à análise de variância, aplicando-se o teste $\mathrm{F}(\mathrm{P} \leq 0,05)$ e 
posteriormente realizou-se a comparação de médias pelo teste de Tukey $(\mathrm{P} \leq 0,05)$. Foi utilizado o programa estatístico SISVAR ${ }^{\circledR}$ (FERREIRA, 2008).

\section{RESULTADOS E DISCUSSÃO}

A B. ruziziensis e a Brachiaria híbrido cv. 'Mulato II' proporcionaram maior competição quando semeadas a lanço, resultando em plantas de milho de menor porte (Tabela 1). A B. ruziziensis também proporcionou menor altura de inserção da espiga (AIE) nesta modalidade. O consórcio da B. decumbens proporcionou maior altura de inserção de espigas (AIE) da cultura do milho quando semeada a lanço e nesta modalidade de consórcio também foi superior na altura de plantas (ALTP) em relação a B. ruziziensis e a Brachiaria híbrido cv. 'Mulato II', enquanto que na altura de inserção da espiga (AIE) foi superior apenas a B. ruziziensis e, quando semeada na linha do milho, foi semelhante a ambas e inferior a B. brizantha. Para o diâmetro médio basal do colmo (DBC) da cultura do milho, apenas quando consorciado com a B. brizantha ocorreu diferença, sendo superior quando esta espécie foi semeada na linha. Já o consórcio com B. ruziziensis reduziu tal atributo na comparação entre as espécies, bem como, por ocasião da semeadura a lanço, esse consórcio foi o que proporcionou menores valores $(94 \mathrm{~cm})$, o que pode prejudicar a colheita mecanizada, aumentando as perdas de espigas não colhidas pela plataforma da colhedora.

Tais resultados demonstram o comportamento da cultura do milho quando em consórcio com braquiárias, influenciados principalmente pela velocidade de estabelecimento da forrageira e aumento da competição por água, luz e nutrientes, o que pode prejudicar o desenvolvimento e consequentemente a produtividade de grãos (PG). Vale ressaltar que plantas maiores acumulam mais nutrientes, translocando-os para as espigas na época de enchimento dos grãos, bem como, após a colheita, depositam maior quantidade de palha no solo. Com relação à diminuição do $\mathrm{DBC}$, plantas com colmos mais finos possuem menor capacidade de translocação de nutrientes e tornam-se mais susceptíveis ao tombamento pelo efeito do vento, das chuvas e do trânsito de maquinários e implementos (adubação de cobertura, aplicação de defensivos e colheita de grãos).

Os melhores resultados de número de fileiras de grãos por espiga (NFG) foram no consórcio a lanço da Brachiaria híbrido cv. 'Mulato II', enquanto que este consórcio proporcionou menor número de grãos por fileira

Tabela 1 - Desdobramento das características da cultura do milho consorciado com forrageiras do gênero Brachiaria em diferentes modalidades. Selvíria-MS, 2006.

\begin{tabular}{|c|c|c|c|c|}
\hline Consórcio & B. brizantha & B. decumbens & B. 'mulato II' & B. ruziziensis \\
\hline & & $--A L T P(\mathrm{~cm})$ & ------------------- & $\mathrm{CV}(\%)=5,2$ \\
\hline Lanço & $228 \mathrm{aAB}^{*}$ & $235 \mathrm{aA}$ & $212 \mathrm{bBC}$ & $202 \mathrm{bC}$ \\
\hline \multirow[t]{2}{*}{ Linha } & $233 \mathrm{aA}$ & $226 \mathrm{aA}$ & $234 \mathrm{aA}$ & $222 \mathrm{aA}$ \\
\hline & & --AIE (cm) --- & - & $\mathrm{CV}(\%)=5,7$ \\
\hline Lanço & $112 \mathrm{aA}^{*}$ & $126 \mathrm{aA}$ & $115 \mathrm{aA}$ & $94 \mathrm{bB}$ \\
\hline \multirow[t]{2}{*}{ Linha } & $129 \mathrm{aA}$ & $117 \mathrm{bB}$ & $112 \mathrm{aB}$ & $109 \mathrm{aB}$ \\
\hline & & $-\mathrm{DBC}(\mathrm{mm})$ & & $\mathrm{CV}(\%)=9,0$ \\
\hline Lanço & $22 \mathrm{bBC}^{*}$ & $27 \mathrm{aA}$ & $25 \mathrm{aAB}$ & $20 \mathrm{aC}$ \\
\hline \multirow[t]{2}{*}{ Linha } & $28 \mathrm{aA}$ & $29 \mathrm{aA}$ & $26 \mathrm{aA}$ & $22 \mathrm{aB}$ \\
\hline & & ---NFG------- & -------------- & $\mathrm{CV}(\%)=11,7$ \\
\hline Lanço & $15,2 \mathrm{aB}^{*}$ & $16,4 \mathrm{aAB}$ & $19,2 \mathrm{aA}$ & $16,0 \mathrm{aAB}$ \\
\hline \multirow[t]{2}{*}{ Linha } & $14,8 \mathrm{aA}$ & $14,4 \mathrm{aA}$ & 14,4 bA & $16,4 \mathrm{aA}$ \\
\hline & & ---NGF------ & - & $\mathrm{CV}(\%)=16,7$ \\
\hline Lanço & $30 \mathrm{aA}^{*}$ & $28 \mathrm{aA}$ & $23 \mathrm{bA}$ & $26 \mathrm{aA}$ \\
\hline \multirow[t]{2}{*}{ Linha } & $32 \mathrm{aA}$ & $32 \mathrm{aA}$ & $34 \mathrm{aA}$ & $24 \mathrm{aB}$ \\
\hline & & ---M100 (g) --- & ---------------- & $\mathrm{CV}(\%)=12,0$ \\
\hline Lanço & $30,2 \mathrm{aA}^{*}$ & $29,3 \mathrm{bA}$ & $32,4 \mathrm{aA}$ & $26,8 \mathrm{aB}$ \\
\hline Linha & $32,6 \mathrm{aA}$ & $37,7 \mathrm{aA}$ & $34,2 \mathrm{aA}$ & $30,0 \mathrm{aB}$ \\
\hline
\end{tabular}

*médias seguidas das mesmas letras minúsculas nas colunas e maiúsculas nas linhas, não diferem significativamente pelo teste de Tukey a $5 \%$.

ALTP, AIE, DBC, NFG, NGF e M100: altura de plantas, altura de inserção da espiga principal, diâmetro médio basal do colmo, número de fileiras de grãos por espiga, número de grãos por fileira e massa de 100 grãos a $13 \%$ de umidade, respectivamente. 
(NGF) em relação ao consórcio na linha (Tabela 1), o que não é interessante do ponto de vista sinérgico entre estes dois atributos, por uma possível diminuição do número de grãos por espiga (NGE). O consórcio com B. ruziziensis na linha também reduziu o número de grãos por fileira (NGF) em relação ao consórcio a lanço. Independente da modalidade de consórcio, a $\boldsymbol{B}$. ruziziensis proporcionou menor massa de 100 grãos (M100) em relação aos consórcios com as demais braquiárias. O consórcio a lanço da $\boldsymbol{B}$. decumbens também apresentou tal comportamento em relação ao consórcio na linha, reflexo possivelmente da menor translocação de fotoassimilados para a granação em virtude de colmos mais finos.

Na tabela 2, verifica-se que, entre as espécies forrageiras, o consórcio com a B. ruziziensis reduziu o comprimento da espiga (CE), em virtude do menor número de grãos por fileira (NGF) (Tabela 1). Tal fato refletiu em menor massa de grãos por espiga (MGE) e, consequentemente, diminuição da produtividade de grãos (PG) de milho, principalmente em relação ao consórcio com $\boldsymbol{B}$. decumbens, que se destacou com a maior produtividade, entretanto, não diferindo em relação ao consórcio com a Brachiaria híbrido cv. 'Mulato II' e a B. brizantha.

A menor competitividade da B. decumbens, principalmente quando semeada na linha do milho, pode ser explicada pelas suas características citadas por PIRES (2006), com ênfase principalmente ao seu hábito de crescimento decumbente, menor exigência em fertilidade do solo e tolerância ao sombreamento parcial, sendo uma espécie menos agressiva do que às demais, principalmente em condições adversas como as impostas no consórcio. Com relação à B. ruziziensis, essa espécie vem sendo recomendada para sistemas de ILP, principalmente por proporcionar rápida cobertura do solo, boa composição bromatológica, excelente reciclagem de nutrientes, facilidades na sua dessecação e produção uniforme de sementes (PIRES, 2006; TRECENTI, 2005). No entanto, no presente trabalho, a diminuição da produtividade de grãos (PG) de milho quando consorciado com esta espécie, pode ter ocorrido em função da utilização de sementes peletizadas. Segundo BAUDET \& PERES (2004), essa técnica favorece a germinação em função da melhor absorção de água e oxigênio, além da eficiência de possíveis hormônios, nutrientes e inoculantes utilizados no recobrimento da semente, já que RENARD \& CAPELLE (1976) afirmaram que a reduzida germinação de sementes de $\boldsymbol{B}$. ruziziensis, resultante da dormência, pode ser devida à restrição na difusão de oxigênio.

PARIZ et al. (2010) também verificaram qualidade fisiológica inferior de sementes de $\boldsymbol{B}$. ruziziensis (sem peletização) em relação às de $\boldsymbol{B}$. brizantha cv. 'Marandu', refletindo em menor produtividade de massa seca após o consórcio simultâneo com a cultura do milho, ao longo de quatro cortes no inverno-primavera. Portanto, a peletização das sementes de B. ruziziensis pode ter proporcionado maior velocidade de emergência e crescimento das plântulas, acarretando, provavelmente, no aumento da competição com as plantas de milho. Assim, recomendam-se novos estudos com técnicas que viabilizem o consórcio entre essas espécies, principalmente em relação à densidade de semeadura da forrageira quando suas sementes forem peletizadas. A utilização de subdoses de herbicida graminicida após a emergência da forrageira também pode ser uma alternativa viável para reduzir a competição.

Conforme KLUTHCOUSKI et al. (2000); FOLONI et al. (2009), a deposição do fertilizante de

Tabela 2 - Médias dos componentes da produção e produtividade de grãos por ha a $130 \mathrm{~g} \mathrm{~kg}^{-1}$ de umidade (PG) da cultura do milho consorciado com forrageiras do gênero Brachiaria em diferentes modalidades. Selvíria-MS, 2006.

\begin{tabular}{|c|c|c|c|c|c|c|}
\hline Consórcio & $\operatorname{EFP}\left(\right.$ plantas $\left.h^{-1}\right)$ & NE (espigas ha $\left.{ }^{-1}\right)$ & $\mathrm{CE}(\mathrm{cm})$ & NGE & MGE (g) & PG $\left(\mathrm{kg} \mathrm{ha}^{-1}\right)$ \\
\hline B. brizantha & $48.333^{\mathrm{ns}}$ & $48.333^{\text {ns }}$ & $18,0 \mathrm{ab}^{*}$ & $459,7^{\text {ns }}$ & $143,8 \mathrm{a}^{*}$ & $7.015 \mathrm{ab}^{*}$ \\
\hline B. decumbens & 52.777 & 52.777 & $19,3 \mathrm{a}$ & 459,4 & $152,7 \mathrm{a}$ & $7.963 \mathrm{a}$ \\
\hline B. mulato II & 46.667 & 46.667 & $19,5 \mathrm{a}$ & 476,6 & $154,9 \mathrm{a}$ & $7.310 \mathrm{ab}$ \\
\hline B. ruziziensis & 55.000 & 53.889 & $16,7 \mathrm{~b}$ & 390,1 & $102,1 \mathrm{~b}$ & $5.419 \mathrm{~b}$ \\
\hline Lanço & $50.277^{\mathrm{ns}}$ & $49.722^{\mathrm{ns}}$ & $18,4^{\mathrm{ns}}$ & $441,9^{\text {ns }}$ & $130,4 \mathrm{~b}$ & $6.371 \mathrm{~b}$ \\
\hline Linha & 51.111 & 51.111 & 18,3 & 451,0 & $144,8 \mathrm{a}$ & $7.433 \mathrm{a}$ \\
\hline $\mathrm{CV}(\%)$ & 18,3 & 17,7 & 9,8 & 19,1 & 16,7 & 17,6 \\
\hline
\end{tabular}

${ }^{\text {ns } m e ́ d i a s ~ n a ̃ o ~ d i f e r e m ~ s i g n i f i c a t i v a m e n t e ~ p e l o ~ t e s t e ~ d e ~ T u k e y ~ a ~ 5 \% ; ~}$

*médias seguidas das mesmas letras nas colunas, não diferem significativamente pelo teste de Tukey a $5 \%$.

EFP, NE, CE, NGE e MGE: estande final de plantas, número de espigas ha $^{-1}$, comprimento de espiga, número de grãos por espiga e massa de grãos por espiga, respectivamente. 
semeadura misturado com as sementes da espécie forrageira em profundidades abaixo de $0,05 \mathrm{~m}$ permite $\mathrm{o}$ atraso da germinação e emergência, de maneira a diminuir a competição com a cultura produtora de grãos. Dessa forma, as diferentes profundidades de semeadura na linha e a lanço $(0,08$ e $0,05 \mathrm{~m}$, respectivamente) podem ter influenciado os resultados do presente estudo. Além disso, geralmente o efeito da salinidade (principalmente do cloreto de potássio) é intensificado na fase de plântula, prejudicando o desenvolvimento inicial das culturas, podendo este fato, também ter ocorrido no caso da semeadura das forrageiras na mesma linha do milho, na qual as sementes das forrageiras foram misturadas ao adubo de semeadura e depositadas no mesmo local. Resultados semelhantes foram verificados por MATEUS et al. (2007), utilizando fertilizante formulado granulado até os períodos de aproximadamente 38 horas após a mistura das sementes de B. brizantha, enquanto que LIMA et al. (2010) recomendam tal mistura até 12 horas.

$\mathrm{Na}$ comparação entre modalidades de consórcio, a produtividade de grãos (PG) de milho, quando consorciado com as braquiárias na linha, foi superior em $1.062 \mathrm{~kg} \mathrm{ha}^{-1}$ de grãos (Tabela 2). Tal resultado pode ser atribuído à maior massa de grãos por espiga, mostrando o efeito deste atributo na produtividade de grãos e a importância de colmos mais grossos na translocação de fotoassimilados para a produção de espigas mais pesadas. Assim, além da especificidade e exigências dos diferentes híbridos de milho, avaliações relacionadas à arquitetura da planta podem definir com clareza o efeito da competição entre as espécies, sendo que, em geral, a capacidade de interceptação da radiação incidente está relacionada ao índice de área foliar (AMARAL FILHO et al., 2005) e fatores como envergadura da folha, desfolhamento, deficiência de nutrientes e condições de estresse por déficit hídricos comprometem a fisiologia da planta.

Na semeadura a lanço, ocorreu uma melhor distribuição das plantas de braquiária na área, já que, apesar da mesma densidade de plantas em ambos os consórcios ( 8 a 10 plantas $\mathrm{m}^{2}$ ), na semeadura em linha, estas se concentraram a cada $0,90 \mathrm{~m}$ (espaçamento do milho), ocorrendo inclusive, competição inicial dentro da espécie. Assim, a semeadura a lanço favoreceu o crescimento inicial da forrageira e, apesar de não afetar o estande final de plantas (EFP) de milho, comprometeu posteriormente a produtividade de grãos, visto que, no momento de enchimento dos grãos, a forrageira se encontrava plenamente instalada. No entanto, as produtividades de grãos do presente trabalho foram superiores às obtidas por BORGHI et al. (2004), no mesmo local sob SSD num Latossolo Vermelho distrófico, em cultivo exclusivo da cultura do milho.

Na tabela 3, com exceção da B. brizantha, verifica-se efeito da modalidade de consórcio na produtividade de massa seca (PMS) das espécies forrageiras, sendo que o consórcio na linha de semeadura do milho resultou em redução deste atributo. Comparando as espécies consorciadas na linha de semeadura do milho, verifica-se que a PMS da Brachiaria 'Mulato II' foi inferior em relação à $\boldsymbol{B}$. brizantha e $\boldsymbol{B}$. decumbens. No consórcio a lanço, a $\boldsymbol{B}$. ruziziensis apresentou maior PMS, neste caso, com destaque também para a B. decumbens. Com relação à

Tabela 3 - Desdobramento da produtividade de massa seca (PMS) e médias da porcentagem de matéria seca (\% MS) de forrageiras do gênero Brachiaria consorciadas com a cultura do milho em diferentes modalidades. Selvíria-MS, 2006.

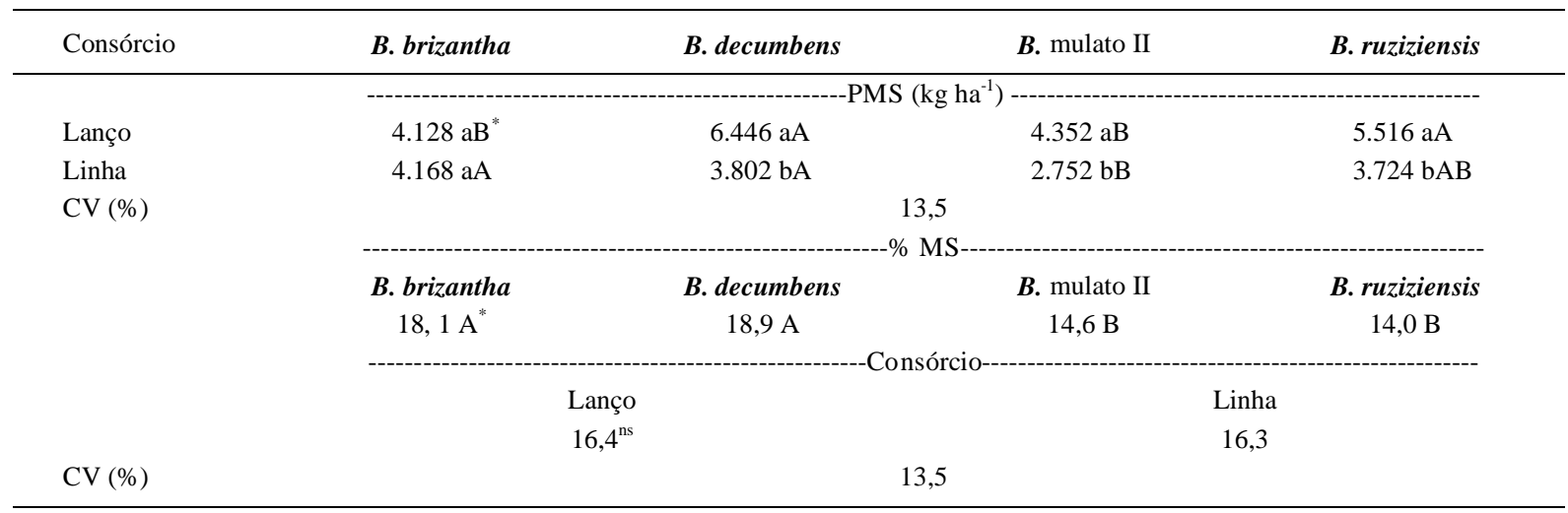

\footnotetext{
${ }^{\text {ns }}$ médias não diferem significativamente pelo teste de Tukey a 5\%;

*médias seguidas das mesmas letras minúsculas nas colunas e maiúsculas nas linhas, não diferem significativamente pelo teste de Tukey a $5 \%$.
}

Ciência Rural, v.41, n.5, mai, 2011. 
porcentagem de matéria seca (\% MS), não se verificou interação entre as braquiárias e as modalidades de consórcio. No entanto, a $B$. brizantha a a B. decumbens apresentaram menor umidade, o que é favorável do ponto de vista de armazenamento, transporte, ensilagem e/ou fenação.

Tais resultados podem ser explicados pelo comportamento das espécies forrageiras no consórcio com o milho na competição por água, luz e nutrientes, sendo que, no consórcio a lanço, os resultados podem ser explicados pelas melhores condições de emergência e crescimento já descritas anteriormente. No entanto, em função das condições climáticas favoráveis nesta época do ano (Figura 1), após a colheita do milho, as forrageiras se encontravam plenamente estabelecidas, com satisfatório acúmulo de massa seca, podendo ser disponibilizadas a corte ou pastejo. Resultados semelhantes foram obtidos por FOLONI et al. (2009), em que o potencial de germinação e emergência da $\boldsymbol{B}$. brizantha foi diminuído pela deposição das sementes abaixo de $0,05 \mathrm{~m}$ no solo e pela mistura destas ao adubo de semeadura, porém, os indivíduos remanescentes apresentaram produtividade de massa seca (PMS) superior, pela maior oferta de nutrientes. Assim, em função deste potencial de crescimento, no consórcio em linha, a B. brizantha se igualou ao consórcio a lanço.

Posteriormente à colheita do milho, houve a formação da pastagem para a pecuária, a qual foi avaliada no presente estudo, sendo dessecada no outono de 2007 para formação de palhada ao feijão de inverno irrigado, demonstrando a possibilidade de uso intensivo da área durante todo o ano.

\section{CONCLUSÃO}

As forrageiras consorciadas a lanço, com destaque para a Brachiaria ruziziensis proporcionaram menor desenvolvimento das plantas de milho, bem como menores valores de componentes da produção e produtividade de grãos.

Apesar de satisfatórias produtividades de massa seca (acima de $2.500 \mathrm{~kg} \mathrm{ha}^{-1}$ ), com exceção da Brachiaria brizantha, as demais espécies consorciadas a lanço foram superiores às consorciadas na linha, com destaque para a Brachiaria decumbens e a Brachiaria ruziziensis com maior adaptabilidade e produtividade de forragem no consórcio com milho em sistema de integração lavoura-pecuária.

\section{REFERÊNCIAS}

ALLEN, V.G. et al. Integrated irrigated crop-livestock systems in dry climates. Agronomy Journal, Madison, v.99, n.2, p.346-360, 2007. Disponível em: <https://www.agronomy.org/ p u b l i c a t i o n s / a j/a r t i c l e s / 9 9/2/ 346 ?highlight=JmFydGljbGVfdm9sdW11PTk5JnE9KGlzc3VlO jIpJmFydGljbGVfZmlyc3RwYWdlPTM0NiZxPShqb3VybmFsOm FqKSZsZW49MTAmc3RhcnQ9MSZzdGVtPWZhbHNIJnNvcnQ9>. Acesso em: 03 mar. 2011. doi: 10.2134/agronj2006.0148.

ALVARENGA, R.C. et al. Cultura do milho na integração lavoura-pecuária. Informe Agropecuário, Belo Horizonte, v.27, n.233, p.106-126, 2006.

AMARAL FILHO, J.P. et al. Espaçamento, densidade populacional e adubação nitrogenada na cultura do milho. Revista Brasileira de Ciência do Solo, Viçosa, v.29, n.3, p.467-473, 2005. Disponível em: <http://www.scielo.br/ s cie lo.ph p s c ri p t $=$ sci pd f \& pid = S $0100-$ $06832005000300017 \& \operatorname{lng}=p t \& n r m=i s o \& t \operatorname{lng}=p t>$. Acesso em: 03 mar. 2011.

BALBINOT JÚNIOR, A.A. et al. Integração lavoura-pecuária: intensificação de uso de área agrícolas. Ciência Rural, Santa Maria, v.39, n.6, p.1925-1933, 2009. Disponível em: <http:/ $/ \mathrm{www}$. scielo.br/scielo.php? script $=$ sci_pdf\&pid=S0103$84782009000600048 \& \operatorname{lng}=p t \& n r m=i s o \& t \operatorname{lng}=p t>$. Acesso em: 03 mar. 2011.

BAUDET, L; PERES, W. Recobrimento de sementes. Disponível em: <http://www.seednews.inf.br/portugues/seed81/ artigocapa81.shtml>. Online. Acesso em: 23 jun. 2009.

BORGHI, E.; CRUSCIOL, C.A.C. Produtividade de milho, espaçamento e modalidade de consorciação com Brachiaria brizantha no SPD. Pesquisa Agropecuária Brasileira, Brasília, v.42, n.2, p.163-171, 2007. Disponível em: <http:// www.scielo.br/pdf/pab/v42n2/04.pdf>. Acesso em: 03 mar. 2011.

BORGHI, E. et al. Adubação por área e por planta, densidade populacional e desenvolvimento do milho em função do sistema de manejo do solo. Acta Scientiarum: Agronomy, Maringá, v.26, n.3, p.337-345, 2004. Disponível em: <http:// periodicos.uem.br/ojs/index.php/ActaSciAgron/article/view/ 1840/1282>. Acesso em: 03 mar. 2011. doi: 10.4025/ actasciagron.v26i3.1840.

CARVALHO, P.C.F. et al. Managing grazing animals to achieve nutrient cycling and soil improvement in no-till integrated systems. Nutrient Cycling in Agroecosystems. Amsterdã, v.88, n.2, p.259-273, 2010. Disponível em: <http:// www.springerlink.com/content/0315261455v540m1/>. Acesso em: 03 mar. 2011. doi: 10.1007/s10705-010-9360-x.

EMBRAPA - Centro Nacional de Pesquisa de Solos. Sistema brasileiro de classificação dos solos. Rio de Janeiro: EMBRAPA Solos, 1999. 306p.

EUCLIDES, V.P.B. et al. Brazilian scientific progress in pasture research during the first decade of XXI century. Revista Brasileira de Zootecnia, Viçosa, v.39, supl. especial, p.151168, 2010. Disponível em: <http://www.scielo.br/pdf/rbz/ v39sspe/18.pdf>. Acesso em: 03 mar. 2011.

FERREIRA, D.F. SISVAR: um programa para análises e ensino de estatística. Científica Sumposium, Lavras, v.6, n.2, p.3641, 2008. Disponível em: <http://www.fadminas.org.br/ symposium/>. Acesso em: 03 mar. 2011. 
FOLONI, J.S.S. et al. Instalação de espécie forrageira em razão da profundidade no solo e contato com fertilzante formulado NPK. Pesquisa Agropecuária Tropical, Goiânia, v.39, n.1, p.7-12, 2009. Disponível em: <http://www.revistas.ufg.br/ index.php/pat/article/view/3313/4462>. Acesso em: 03 mar. 2011 .

FONTANELI, R.S. et al. Lucratividade e risco de sistemas de produção de grãos com pastagens, sob sistema plantio direto. Ciência Rural, Santa Maria, v.36, n.1, p.51-57, 2006. Disponível em: <http://www.scielo.br/scielo.php?script=sci_pdf\&pid=S0103$84782006000100008 \& \operatorname{lng}=\mathrm{pt} \& \mathrm{nrm}=\mathrm{iso} \& \mathrm{tlng}=\mathrm{pt}>$. Acesso em: 03 mar. 2011.

KLUTHCOUSKI, J. et al. Sistema Santa Fé - Tecnologia Embrapa: integração lavoura-pecuária pelo consórcio de culturas anuais com forrageiras, em áreas de lavoura, nos sistemas direto e convencional. Santo Antonio de Goiás: Embrapa Arroz e Feijão, 2000. 28p. (Circular Técnica, 38).

KLUTHCOUSKI, J.; YOKOYAMA, L.P. Opções de integração lavoura-pecuária. In: KLUTHCOUSKI, J. et al. Integração Lavoura-Pecuária. Santo Antonio de Goiás: Embrapa Arroz e Feijão, 2003. Cap.4, p.131-141.

LIMA, E.V. et al. Mistura de sementes de Brachiaria brizantha com fertilizante NPK. Ciência Rural, Santa Maria, v.40, n.2, p.471-474, 2010. Disponível em: <http://www.scielo.br/ s c i e 1 o.ph p s c ri p t $=$ s c i $\_$p d f \& p i d = S 0103 $84782010000200035 \& \operatorname{lng}=\mathrm{en} \& \mathrm{nrm}=\mathrm{iso} \& \operatorname{tn} \mathrm{ln}=\mathrm{pt}>$. Acesso em: 03 mar. 2011. doi: 10.1007/s10705-010-9360-x.

LUNARDI, R. et al. Rendimento de soja em sistema de integração lavoura-pecuária: efeito de métodos e intensidade de pastejo. Ciência Rural, Santa Maria, v.38, n.3, p.795-801, 2008. Disponível em: $<$ http://www.scielo.br/scielo.php?script=sci_pdf \&pid=S0103$84782008000300032 \& \operatorname{lng}=\mathrm{pt} \& \mathrm{nrm}=\mathrm{iso} \& \operatorname{lng}=\mathrm{pt}>$. Acesso em: 03 mar. 2011. doi: 10.1007/s10705-010-9360-x.

MACEDO, M.C.M. Integração lavoura e pecuária: o estado da arte e inovações tecnológicas. Revista Brasileira de Zootecnia, Viçosa, v.38, supl. especial, p.133-146, 2009. Disponível em: <http://www.scielo.br/pdf/rbz/v38nspe/ v38nspea15.pdf>. Acesso em: 03 mar. 2011.

MATEUS, G.P. et al. Fontes e períodos de contato de fertilizantes e germinação de sementes de Brachiaria brizantha. Revista Brasileira de Ciência do Solo, Viçosa, v.31, n.1, p.177-183, 2007. Disponível em: <http://dx.doi.org/ 10.1590/ S0100-06832007000100018>. Acesso em: 03 mar. 2011. doi: 10.1590/S0100-06832007000100018.

PARIZ, C.M. et al. Qualidade fisiológica de sementes de Brachiaria e avaliação da produtividade de massa seca, em diferentes sistemas de integração lavoura-pecuária sob irrigação. Pesquisa Agropecuária Tropical, Goiânia, v.40, n.3, p.330340, 2010. Disponível em: <http://www.revistas.ufg.br/ index.php/pat/article/view/6590/7809>. Acesso em: 03 mar. 2011. doi: 10.5216/pat.v40i3.6590.

PIRES, W. Manual de pastagem: formação, manejo e recuperação. Viçosa: Aprenda Fácil, 2006. 302p.

RENARD, C.; CAPELLE, P. Seed germination in Ruzizi grass (Brachiaria ruziziensis Germain \& Everard). Australian Journal of Botany, Collingwood, v.24, n.4, p.437-446, 1976. Disponível em: <http://www.publish.csiro.au/nid/65/paper/ BT9760437.htm>. Acesso em: 03 mar. 2011. doi: 10.1071/ BT 9760437.

SHAPIRO, S.S.; WILK, M.B. An analysis of variance test for normality (complete samples). Biometrika, Oxford, v.52, n.3-4, p.591-611, 1965. Disponível em: <http:// biomet.oxfordjournals.org/content/52/3-4/591.full.pdf+html> . Acesso em: 03 mar. 2011. doi: 10.1093/biomet/52.3-4.591.

SILVA, A.A. et al. Sistemas de coberturas de solo no inverno e seus efeitos sobre o rendimento de grãos do milho em sucessão. Ciência Rural, Santa Maria, v.37, n.4, p.928-935, 2007. Disponível em: $<$ http://www.scielo.br/scielo.php?script=sci_pdf\&pid=S0103$84782007000400002 \& \operatorname{lng}=\mathrm{pt} \& \mathrm{nrm}=\mathrm{iso} \& \operatorname{lng}=\mathrm{pt}>$. Acesso em: 03 mar. 2011.

SULC, R.M.; TRACY, B.F. Integrated crop-livestock systems in the U.S. Corn Belt. Agronomy Journal, Madison, v.99, n.2, p.335-345, 2007. Disponível em: <https://www.agronomy.org/ publications/search?search $\% 5 \mathrm{~B}-3 \% 5 \mathrm{D}=\&$ search Type $\% 5 \mathrm{~B}-$ $3 \% 5 \mathrm{D}=\mathrm{A}$ y $\&$ search $\% 5 \mathrm{~B}-2 \% 5 \mathrm{D}=\&$ se archFields $\% 5 \mathrm{~B}-$ $2 \% 5 \mathrm{D} \% 5 \mathrm{~B}$ Author $\% 5 \mathrm{D}=\mathrm{Auth}$ or $\&$ search Type $\% 5 \mathrm{~B}-$ $2 \% 5 \mathrm{D}=\mathrm{Phrase} \&$ search $\% 5 \mathrm{~B}-1 \% 5 \mathrm{D}=\&$ searchFields $\% 5 \mathrm{~B}-$ $1 \% 5 \mathrm{D} \% 5 \mathrm{~B} \mathrm{~T}$ it le $\% 5 \mathrm{D}=\mathrm{Tit} 1$ e \& search Type $\% 5 \mathrm{~B}-$ $1 \% 5 \mathrm{D}=$ Phrase $\&$ volume $=99 \&$ issue $=2 \&$ year $=\&$ first page $=335 \&$ search $\% 5 \mathrm{~B} 0 \% 5 \mathrm{D}=>$. Acesso em: 03 mar. 2011. doi: 10.2134/agronj2006.0086.

TRECENTI, R. Técnicas de consórcio ajudam na formação de palha para o plantio direto. Revista Plantio Direto, Passo Fundo, v.86, on-line, 2005. Disponível em: <http:// www.plantiodireto.com.br/?body=cont_int\&id=616>. Acesso em: 04 dez. 2009. 